\title{
Methodology of constructing driving cycles by the synthesis
}

\author{
Akmal Mukhitdinov ${ }^{*}$, Kamoliddin Ziyaev, Janserik Omarov, and Shokhsanam Ismoilova \\ Tashkent State Transport University, Tashkent, Uzbekistan
}

\begin{abstract}
The difference in the dynamics of the development of motorization in the regions of the world, the levels of traffic organization, determines the need to develop a methodology for specific operating conditions. Improvement of the existing driving cycles and methods of their development, which characterize the real operating conditions, is of great importance. An important task is considered the implementation of targeted research to improve automobile operation efficiency of vehicles by introducing modern information technologies into the process of determining the driving cycles, modernizing the design parameters of vehicles by assessing the influence of driving conditions when rationing fuel consumption, developing methods for choosing the design parameters of vehicles and the most adapted vehicle for specific operating conditions. The article provides a systematic analysis of scientific research of methodology for constructing driving cycles, factors influencing the performance and driving modes, as well as the fuel consumption of the car. The methodology for constructing a standard driving cycle for specific urban operating conditions is given based by synthesizing on passenger car driving modes in the city.
\end{abstract}

\section{Introduction}

The indicators of fuel economy, the toxicity of exhaust gases, and energy efficiency of vehicles defined in the standard driving cycles do not correspond to the values of real operating conditions. The standardized driving cycles in the national standards, in the UNECE Regulation No. 83, are aimed at determining the dynamics of improving a vehicle design. A new stage in improving the methodology of determining the indicators of environmentally safe and fuel efficiency is the organization of on-road cycle tests (AVL). Closer to real conditions, this method is also limited in its versatility in applying a wide range of operating conditions.

There are several methods for assessing the energy efficiency of road transport [1], including regulatory [2]. Recently, cars have been classified by energy efficiency; simultaneously, the criterion of energy efficiency is the amount of $\mathrm{CO} 2$ in the composition of exhaust gases per unit of distance traveled [3]. This criterion is also determined on the standardized driving cycles [4-8].

\footnotetext{
*Corresponding author: akmalmukhitdinov@gmail.com
} 
According to its individual properties, there are several dozens of international, national, company standardized driving cycles, characterizing operating conditions or intended for comparative evaluation of design perfection as a whole. The indicators of these criteria can only serve for a comparative evaluation of designs. Differences in driving conditions in a wide range of vehicles do not unambiguously manifest the indicators given in technical specifications by manufacturers [9-10].

The standard driving cycle of passenger cars is one of the main determinants of energy consumption. As a criterion for assessing energy efficiency, it is possible to use useful traction energy expended per unit travel of the driving cycle $(\mathrm{J} / \mathrm{m})$. An approximate criterion is proposed in [11] in the form of a vehicle's run per $100 \mathrm{~km}(\mathrm{~kJ} / 100 \mathrm{~km})$. However, the proposed dependence for determining the energy requirement for movement on a driving cycle gives the value of the approximate average traction energy due to the approximation of the force resistance to movement in the context of its components. For a more accurate determination of the integral value of the useful traction energy on the car's driving wheels, it is necessary to determine the main energy ratios of the car in the phases of the driving cycle.

The difference in the analyzed more than 200 standard driving cycles comes from the difference in the car manufacturer's requirements. These cycles aim to improve the design to improve one property of the car and insufficiently characterize the actual operating conditions. The adaptability of a vehicle to a specific operating condition, especially the issues of determining fuel efficiency, environmental safety, energy efficiency, and other properties, determine the availability of an appropriate driving cycle. This explains the need to create a methodology for developing driving cycles [12-21].

Therefore, this work aims to develop a methodology for determining the standardized driving cycle of passenger cars for real specific urban operating conditions.

Research objectives:

development of a criterion for assessing the degree of complexity of driving traffic conditions and driving cycle;

development of methodology for analyzing statistical data on the driving modes of vehicles in urban conditions;

development of a methodology for determining the standard driving cycle for urban operating conditions by synthesizing vehicle driving modes.

\section{Materials and Methods}

Kinematic parameter, which includes instantaneous-medium-maximum-minimum speed, acceleration, deceleration, idle time, is the indicator of vehicle movement. The dynamics of changes in these parameters form the average technical speed of the vehicle, which varies depending on the hours of the day, days of the week, and season. The degree of accuracy of the generated driving cycle is evaluated by comparing it with the city's actual average technical speed. To determine the average technical speed in Tashkent during the year, its values were recorded for several passenger cars using "Teltonika FM 1000" equipment. A variation series from the recorded results were constructed, and the criterion of $\mathrm{C}$ determined the number of their intervals. Brooks [...]

$$
k \leq 5 \log n
$$

where: $k$ is minimum number of intervals; $n$ is number of observations.

If the difference between the highest and the lowest values of the technical speed 
(variation width) is divided by the number of intervals, we get the interval step

$$
d=\frac{x_{\max }-x_{\min }}{k}=\frac{x_{\max }-x_{\min }}{5 \log n} .
$$

At the same time, the average technical speed

$$
V_{a v}=\frac{1}{n} \sum_{i=1}^{n} X_{i}=\frac{1}{n} \sum_{i=1}^{n} x_{i} n_{i}
$$

where: $\mathrm{x}_{\mathrm{i}}$ is fixed value of technical speed, $\mathrm{km} / \mathrm{h}$.

Then the standard deviation (variance)

$$
\sigma_{x}=\sqrt{\frac{\sum\left(X_{i}-V_{a v}\right)^{2}}{n}} .
$$

Table 1. Methods for determining the average technical speeds

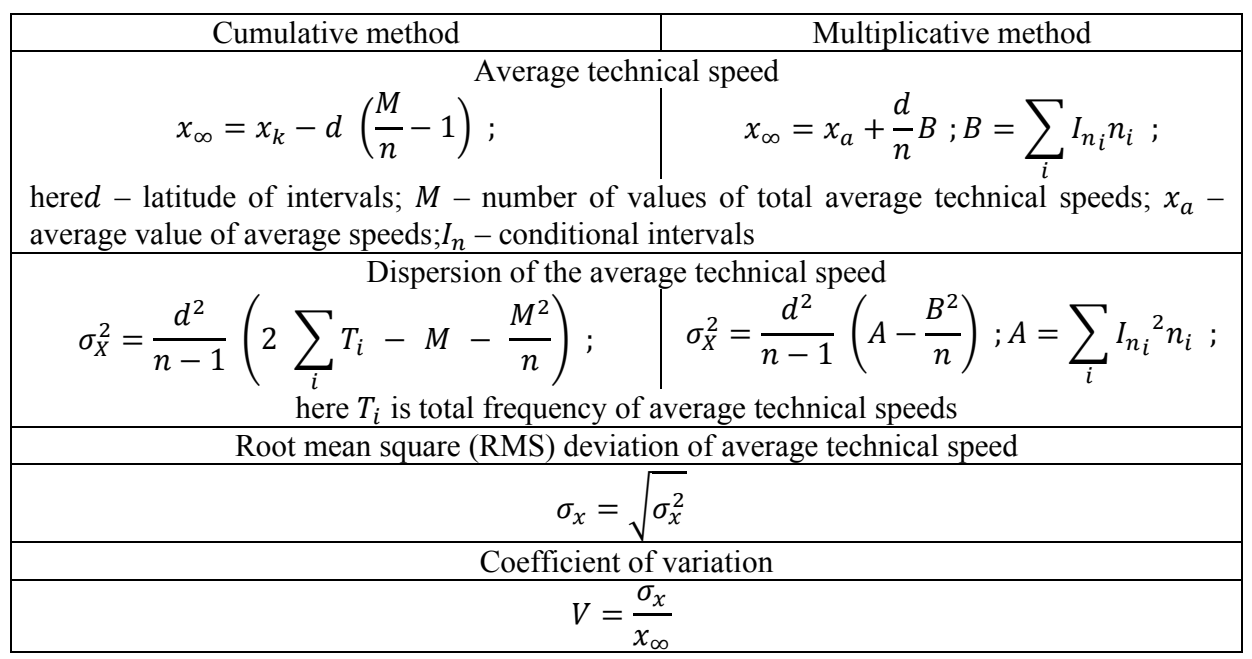

There are several methods for calculating the mean value and the standard deviation. The results of the analysis of average technical speeds by multiplicative and cumulative methods showed that they differ by no more than $2 \%$. For this reason, when determining the average technical speeds of vehicles, it is advisable to use both methods (Table 1). If the coefficient of variation is no more than 0.30 , the equation is considered homogeneous, and the number of observations of the average technical speed is sufficient.

The construction of the urban driving cycle required the synthesis of modes and traffic indicators of cars. A general view of the functional dependence of the factors affecting the driving modes and indicators:

$$
f(x)=\left(X_{1}, X_{2}, \ldots, X_{n}\right)
$$

where $\mathrm{X}_{1}$ is distance between intersections; $\mathrm{X}_{2}$ is mutual consistency of intersections; 
$\mathrm{X}_{3}$ is vehicle type; $\mathrm{X}_{4}$ are weather and climatic conditions; $\mathrm{X}_{5}$ are geometric parameters of streets; $\mathrm{X}_{6}$ is the composition of traffic flow and traffic intensity; $\mathrm{X}_{7}$ is road surface quality; $\mathrm{X}_{8}$ is travel time in the context of hour, day, week, month.

The driving modes of the cars, determined by experiment, analyzed by the following modes: idling or stopping mode $\left(\mathrm{V}_{\mathrm{a}}=0 ; \omega_{\mathrm{e}}=\omega_{\mathrm{xx}}>0 ; \mathrm{S}=0 ; \mathrm{t}>0\right)$; accelerating $\left(\mathrm{j}_{\mathrm{a}}>0 ; \mathrm{V}_{\mathrm{k}}>\mathrm{V}_{\mathrm{n}}\right.$; $\mathrm{S}>0 ; \mathrm{t}>0)$; steady motion mode $\left(\mathrm{j}_{\mathrm{a}}=0 ; \mathrm{V}_{\mathrm{k}}=\mathrm{V}_{\mathrm{n}} ; \mathrm{S}>0 ; \mathrm{t}>0\right)$; deceleration mode $\left(\mathrm{j}_{\mathrm{a}}<0 ; \mathrm{V}_{\mathrm{k}}<\mathrm{V}_{\mathrm{n}}\right.$; $\mathrm{S}>0 ; \mathrm{t}>0$ ). Vehicle speed indicators were determined taking into account the boundary deviation adopted, according to the UNECE Regulation No. 83, equal to $\pm 1.0 \mathrm{~m} / \mathrm{s}$.

Each of the cycle modes is established by the following principles.

a) Idle or stop mode: if the vehicle's instantaneous speed, $V_{\mathrm{a}_{i}}=0 \operatorname{or} V_{\mathrm{a}_{i}}<1, V_{\mathrm{a}_{i-1}}=$ $V_{\mathrm{a}_{i+1}}=0$, then the following is accepted: the vehicle is idling or stopped and is considered to be $V_{\mathrm{a}_{i}}=V_{c}^{n}=0$ :

$1>\cup_{i=1}^{x} V_{a i} \therefore V_{a i}=V_{c}^{n}=0$ and $/$ or $0=\bigcup_{i=1}^{x} V_{a i} \therefore V_{a i}=V_{c}^{n}=0$.

Here $x$ is the last component, synthesized during $n$. This period lasts until the onset of the next regime, and its total duration is

$$
t_{c}^{n}=t_{c_{x}}^{n}-t_{c_{i}}^{n}
$$

where $\mathrm{t}_{\mathrm{c}_{\mathrm{i}}}^{\mathrm{n}}$ is the start time of idling or stopping in the period $n, \mathrm{c} ; \mathrm{t}_{\mathrm{c}_{\mathrm{x}}}^{\mathrm{n}}$ is time of the end of the idle mode or stop in the period $n$, c.

b) Constant speed driving mode: if the vehicle's instantaneous speed $V_{a_{i}}>V_{a_{i+1}}-1$, $V_{a_{i}}<V_{a_{i+1}}+1, V_{a_{i}}>V_{a_{i+2}}-1 \mathrm{and} V_{a_{i}}<V_{a_{i+2}}+1$, then it is considered that the car is moving at a constant speed

$$
V_{a v}^{n}=\frac{\sum_{i=1}^{x}\left(V_{a v i}^{n} \cdot\left(t_{i+1}^{n}-t_{i}^{n}\right)\right)}{t_{a v}^{n}}
$$

The constant speed mode (period $n_{i}$ ) continues until the start of the next mode, and its total duration is determined by the formula

$$
t_{a v}^{n}=t_{a v_{x}}^{n}-t_{a v_{i}}^{n}
$$

where $\mathrm{t}_{\mathrm{av}_{\mathrm{i}}}^{\mathrm{n}}$ is the beginning of the driving mode with constant speed during the period $n$, $\mathrm{c} ; t_{a v_{x}}^{n}$ is end of constant speed driving mode during $n, \mathrm{c}$.

Using the above equation establishes the values of the constant velocity of the car in the value of the average speed of each period

$$
\bigcup_{i=1}^{x} V_{a v_{i}}^{n}=V_{a v}^{n} .
$$

c) Acceleration mode: $\operatorname{if} V_{c}^{n}<V_{a v}^{n}$ or $V_{a v}^{n}<V_{a v}^{n+1}$, it is assumed that the car moves in the acceleration mode, and the calculations are carried out according to the following expressions:

$$
\begin{gathered}
V_{c}^{n}<V_{a v}^{n} \therefore j_{a c}^{n}=\frac{V_{a v}^{n}}{t_{a c}^{n}} \\
V_{a v}^{n}<V_{a v}^{n+1} \therefore j_{a c}^{n}=\frac{V_{a v}^{n+1}-V_{a v}^{n}}{t_{a c}^{n}} .
\end{gathered}
$$


Mode period $n_{i}$ continues until the onset of the next regime, and its total duration is determined by the formula

$$
t_{a c}^{n}=t_{a c_{x}}^{n}-t_{a c_{i}}^{n}
$$

where $t_{a c i}^{n}$ is start of acceleration mode in the period $n, \mathrm{c} ; t_{a c}^{n}$ is end of acceleration mode in the period $n$, c.

The acceleration values determined by this equation are set to the value of the average acceleration of each period.

d) Deceleration mode: if $V_{a v}^{n}>V_{a v}^{n+1}$ or $V_{a v}^{n}>V_{c}^{n}$, then it is assumed that the car moves in the deceleration mode, and the calculations are carried out according to the following expressions:

$$
\begin{gathered}
V_{a v}^{n}>V_{c}^{n} \therefore j_{d}^{n}=\frac{0-V_{a v}^{n}}{t_{d}^{n}}, \\
V_{a v}^{n}<V_{a v}^{n+1} \therefore j_{d}^{n}=\frac{V_{a v}^{n}-V_{a v}^{n+1}}{t_{d}^{n}} .
\end{gathered}
$$

The period of deceleration mode $n_{i}$ continues until the next mode occurs, and its total duration is determined by the formula

$$
t_{d}^{n}=t_{d_{x}}^{n}-t_{d_{i}}^{n}
$$

where $t_{d_{i}}^{n}$ is start of deceleration mode in the period $n, \mathrm{c} ; t_{d_{x}}^{n}$ is end of deceleration mode in the period $n, \mathrm{c}$.

The deceleration values determined with the help of this equation are set in the value of the average deceleration of each period.

Total driving time of the vehicle:

$$
T_{t}=T_{c}+T_{a v}+T_{a c}+T_{d}
$$

here $T_{t}$ is total idle and stop time equal to

$T_{c}=\sum_{n}^{l} t_{c}^{n},[c]$;

$T_{a v}$ is the total travel time in constant speed mode equal to

$T_{a v}=\sum_{n}^{l} t_{a v}^{n},[c]$;

$T_{a c}$ is the total travel time in acceleration mode equal to

$T_{a c}=\sum_{n}^{l} t_{a c}^{n},[c]$;

$T_{d}$ is the total time of the deceleration mode equal to

$T_{d}=\sum_{n}^{l} t_{d}^{n},[c]$.

The proportion of each traffic mode is determined by the following expressions:

\begin{tabular}{|l|l|}
\hline idle and stop mode & $T_{c}^{\%}=\frac{T_{c}}{T_{t}},[\%] ;$ \\
\hline constant speed mode & $T_{a v}^{\%}=\frac{T_{a v}}{T_{t}},[\%] ;$ \\
\hline acceleration mode & $T_{a c}^{\%}=\frac{T_{a c}}{T_{t}},[\%] ;$ \\
\hline deceleration mode & $T_{d}^{\%}=\frac{T_{d}}{T_{t}},[\%]$. \\
\hline
\end{tabular}

The common path traveled 


$$
S_{t}=S_{a v}+S_{a c}+S_{d}
$$

here $S_{a v}$ is the total distance (m) in the constant-speed mode of motion equal to

$$
S_{a v}=\sum_{n}^{l}\left(V_{a v}^{n} \cdot t_{a v}^{n}\right)
$$

$S_{a c}$ is total path (m) in the acceleration mode equal to

$$
V_{a v}^{n}<V_{a v}^{n+1} \therefore S_{a c}=\sum_{n}^{l}\left(V_{a v}^{n} \cdot t_{a c}^{n}+\frac{j_{a c}^{n} \cdot t_{a c}^{n}{ }^{2}}{2}\right), \text { or } V_{c}^{n}<V_{a v}^{n} \therefore S_{a c}=\sum_{n}^{l}\left(\frac{j_{a c}^{n} \cdot t_{a c}^{n}{ }^{2}}{2}\right)
$$

$S_{d}$ is total path (m) in the deceleration mode equal to

$$
V_{a v}^{n}>V_{a v}^{n+1} \therefore S_{d}=\sum_{n}^{l}\left(V_{a v}^{n+1} \cdot t_{d}^{n}+\frac{j_{d}^{n} \cdot t_{d}^{n^{2}}}{2}\right), \text { or } V_{a v}^{n}>V_{c}^{n} \therefore S_{d}=\sum_{n}^{l}\left(\frac{j_{d}^{n} \cdot t_{d}^{n^{2}}}{2}\right) .
$$

Average vehicle speed $(\mathrm{m} / \mathrm{s})$

$$
V_{a v}^{t}=\frac{S_{t}}{T_{t}}
$$

While preserving the proportion of each driving mode, to form a driving cycle, it is reasonable to reduce the scale of the large data set as follows:

$$
\tau_{t}=\frac{T_{t}}{T_{d c}}
$$

Here $T_{d c}$ is total time of the city standard driving cycle, c.

The duration of each motion mode is translated to the selected scale using the following expressions:

\begin{tabular}{|l|c|}
\hline Idle or stop time (s) & $T_{d c}^{c}=\frac{T_{\mathrm{c}}}{\tau_{t}} ;$ \\
\hline constant speed mode time (s) & $T_{d c}^{a v}=\frac{T_{a v}}{\tau_{t}} ;$ \\
\hline acceleration time (s) & $T_{d c}^{a c}=\frac{T_{a c}}{\tau_{t}} ;$ \\
\hline deceleration time (s) & $T_{d c}^{d}=\frac{T_{d}}{\tau_{t}}$ \\
\hline
\end{tabular}

The analysis of the phases of the modes of motion at a constant speed showed the following. Considering the value of the maximum allowed speed of $70 \mathrm{~km} / \mathrm{h}(19.4 \mathrm{~m} / \mathrm{s})$ in the city from the speed values corresponding to the interval $0-70$, a series of variations, according to the equation of $\mathrm{C}$. Brooks. Constant speed mode is considered at four levels: $\vartheta_{1}^{a v}$ are dense movements ( congestion) with a velocity of $0-5 \mathrm{~m} / \mathrm{s} ; \vartheta_{2}^{a v}$ is movement with average speeds of $5-10 \mathrm{~m} / \mathrm{s} ; \vartheta_{3}^{a v}$ is movement at high speeds of $10-15 \mathrm{~m} / \mathrm{s} ; \vartheta_{4}^{a v}$ is movement with maximum speeds of $15-20 \mathrm{~m} / \mathrm{s}$. The values of the constant velocity $(\mathrm{m} / \mathrm{s})$ for each part are rounded according to the expression

$$
\vartheta_{i}^{a v}=\frac{\sum_{n}^{l} V_{a v}^{n} \cdot t_{a v_{i}}^{n}}{\sum_{n}^{l} t_{a v_{i}}^{n}} \therefore m_{i}<V_{a v}^{n} \leq k_{i},
$$


where $m_{i}$ is initial velocity of the corresponding part, $\mathrm{M} / \mathrm{c} ; k_{i}$ is the final velocity of the corresponding part, $\mathrm{m} / \mathrm{s}$.

According to the scale, the average speeds of each part and their duration are reflected in the driving cycle (Figure 1).

Analysis of the acceleration mode phases, to determine the acceleration values in the driving cycle, the average acceleration values falling in the velocity section of each part

$$
j_{a c_{i}}^{a v}=\frac{\sum_{n}^{l} j_{a c}^{n} \cdot S_{a c_{i}}^{n}}{\sum_{n}^{l} S_{a c_{i}}^{n}} \therefore m_{i}<\vartheta_{i}^{a v} \leq k_{i}
$$

Thus, the number of accelerations between constant velocities of motion falling on the separated parts in the section $\vartheta_{i}^{a v}$,

$$
a_{i}^{a c}=\frac{j_{a c_{i}}^{a v} \sum_{n}^{l} \cdot S_{a c_{i}}^{n}}{\vartheta_{i}^{a v}} \therefore S_{a c_{i}}^{n}=\vartheta_{i}^{a v} t_{a c_{i}}^{n}+\frac{j_{a c_{i}}^{n} \cdot t_{a c_{i}}^{n}{ }^{2}}{2} ; \quad t_{a c_{i}}^{n}=\frac{\Delta V_{a v}^{n}}{j_{a c}^{n}} \therefore m_{i}<\vartheta_{i}^{a v} \leq k_{i} .
$$

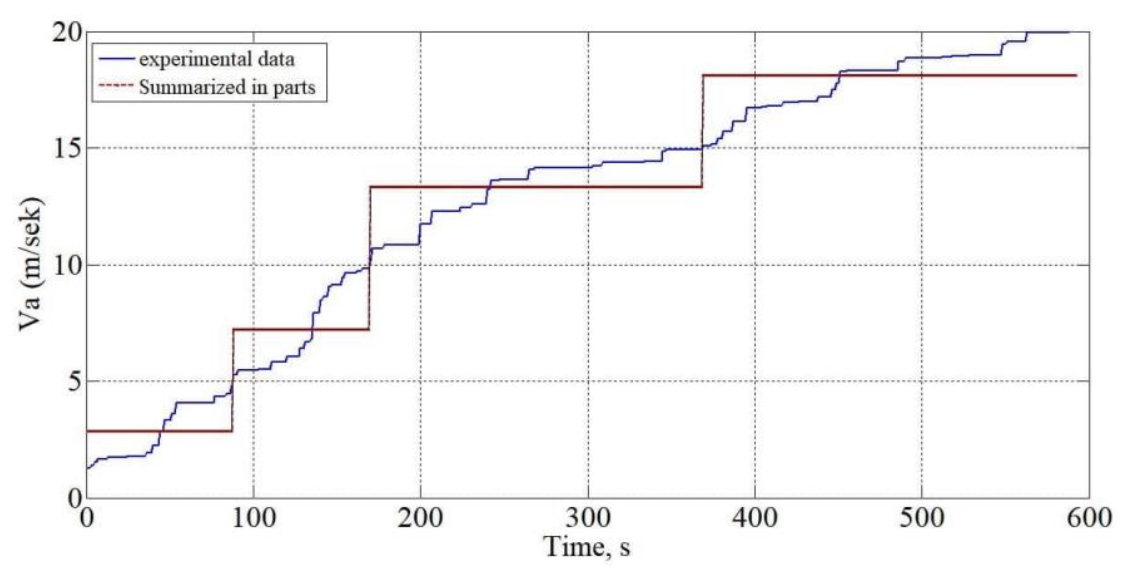

Fig.1. The result of the analysis of the constant-speed mode of the vehicle on the four parts

Deceleration mode phase analysis, to determine the values of decelerations in the driving cycle, the average values of decelerations falling on the velocity section of each part,

$$
j_{d_{i}}^{a v}=\frac{\sum_{n}^{l} j_{d}^{n} \cdot S_{d_{i}}^{n}}{\sum_{n}^{l} S_{d_{i}}^{n}} \therefore m_{i}<\vartheta_{i}^{a v} \leq k_{i}
$$

Thus, the number of decelerations between constant velocities falling on the separated parts in the section $\vartheta_{i}^{a v}$,

$$
a_{i}^{d}=\frac{j_{d_{i}}^{a v} \sum_{n}^{l} \cdot S_{d_{i}}^{n}}{\vartheta_{i}^{a v}} \therefore S_{d_{i}}^{n}=\vartheta_{i}^{a v} t_{d}^{n}+\frac{j_{d_{i}}^{n} \cdot t_{d_{i}}^{n 2}}{2} ; \quad t_{d_{i}}^{n}=\frac{\Delta V_{a v}^{n}}{j_{d}^{n}} \therefore m_{i}<\vartheta_{i}^{a v} \leq k_{i} .
$$

Number of repetitions $N_{c}$ and their duration $T_{\mathrm{x}_{i}}^{\mathrm{c}}$ the idle or stop mode is defined as 


$$
N_{c}=a_{1}^{a c}+1, T_{d c_{i}}^{c}=\frac{T_{d c}^{c}}{N_{c}}
$$

Construction of the driving cycle is performed by synthesizing certain values by analyzing the phases of the vehicle driving modes and their period in scale.

The developed "Computer logic calculation program for constructing an urban driving cycle for passenger cars" allows us to create a driving cycle by synthesizing the values obtained from analyzing the phases of traffic modes of cars.

When the car is moving at a constant speed for a certain distance, the values of the forces of resistance to movement are considered insignificant; respectively, high fuel economy is achieved. An increase in the proportion of acceleration and deceleration in the composition of driving leads to an increase in fuel consumption. Based on this, the relative fuel consumption, which is defined by the formula

$$
\gamma=\frac{Q_{d c}}{Q_{a v}}
$$

where $Q_{d c}$ is fuel consumption in the driving cycle of a passenger car, g;

$Q_{a v}$ is fuel consumption of a passenger car when traveling a driving cycle distance at an average driving speed, $\mathrm{g}$.

Fuel consumption $(\mathrm{g})$ in the urban driving cycle $Q_{d c}$ is

$$
Q_{d c}=\sum G_{\mathrm{c}}+\sum G_{a v}+\sum Q_{a c}
$$

here $G_{\mathrm{c}}$ is fuel consumption in engine idle mode, $\mathrm{g} / \mathrm{s}$;

$G_{a v}$ is fuel consumption when driving at a constant speed, $\mathrm{g} / \mathrm{s}$;

$Q_{a c}$ is fuel consumption in acceleration mode, $\mathrm{g} / \mathrm{s}$.

The fuel consumption $(\mathrm{g})$ of a passenger car when traveling a driving distance with an average driving speed is defined as

$$
Q_{a v}=\frac{N_{T} \cdot g_{e}}{\eta_{t r} \cdot 3600} \cdot t
$$

\section{Results and Discussion}

According to the above method, the average technical speeds by hours of the day, days of the week, and seasons were determined in (Figure2) for the period from July 2018 to July 2019. More than 50 passenger cars were observed, and 105,112 values of average technical speed were recorded. Based on this, it was concluded that the average technical speed of cars in Tashkent city is $25.9 \mathrm{~km} / \mathrm{h}$, and its variation range is: by hours of the day $-11.2 \%$, by days of the week $-6.2 \%$, by seasons of the year $-3.1 \%$. The "Computer program for determining the average technical speed of passenger cars in urban conditions" was developed for fast and reliable processing of a large array of data. 


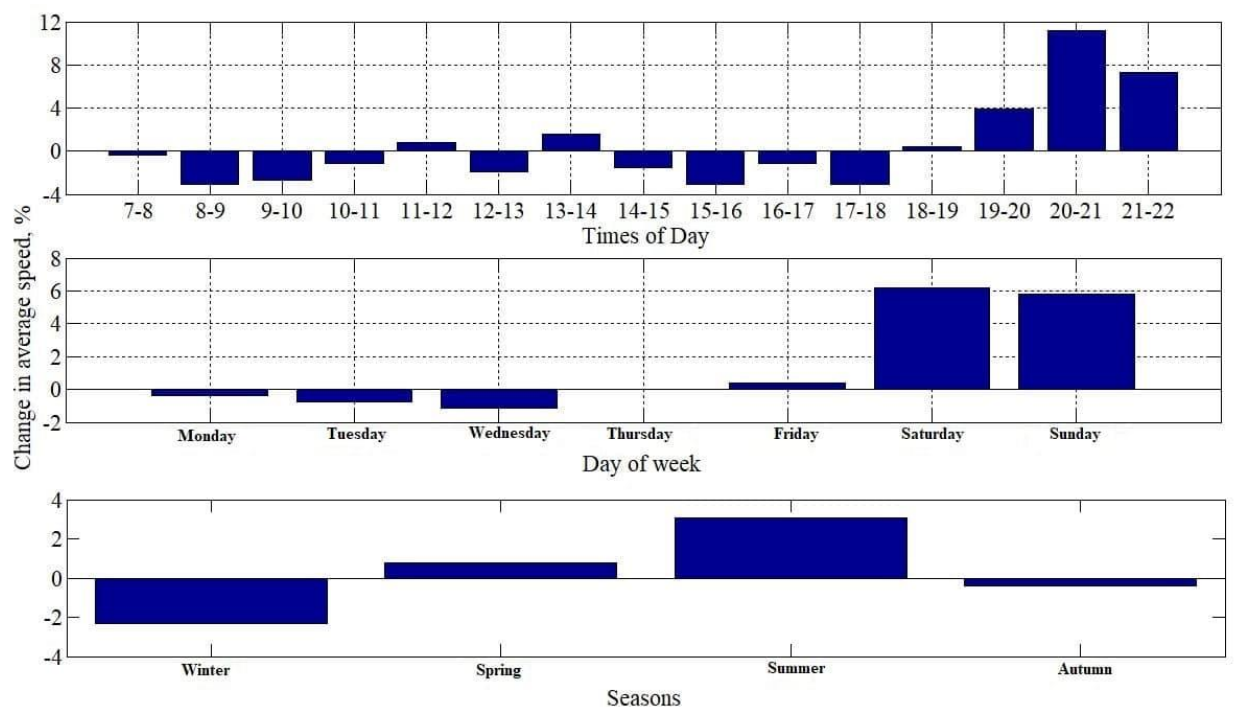

Fig.2. Change in average technical speed cars in Tashkent city

The car movement data set up with the help of the above logical calculation program are shown graphically in Figure 3.

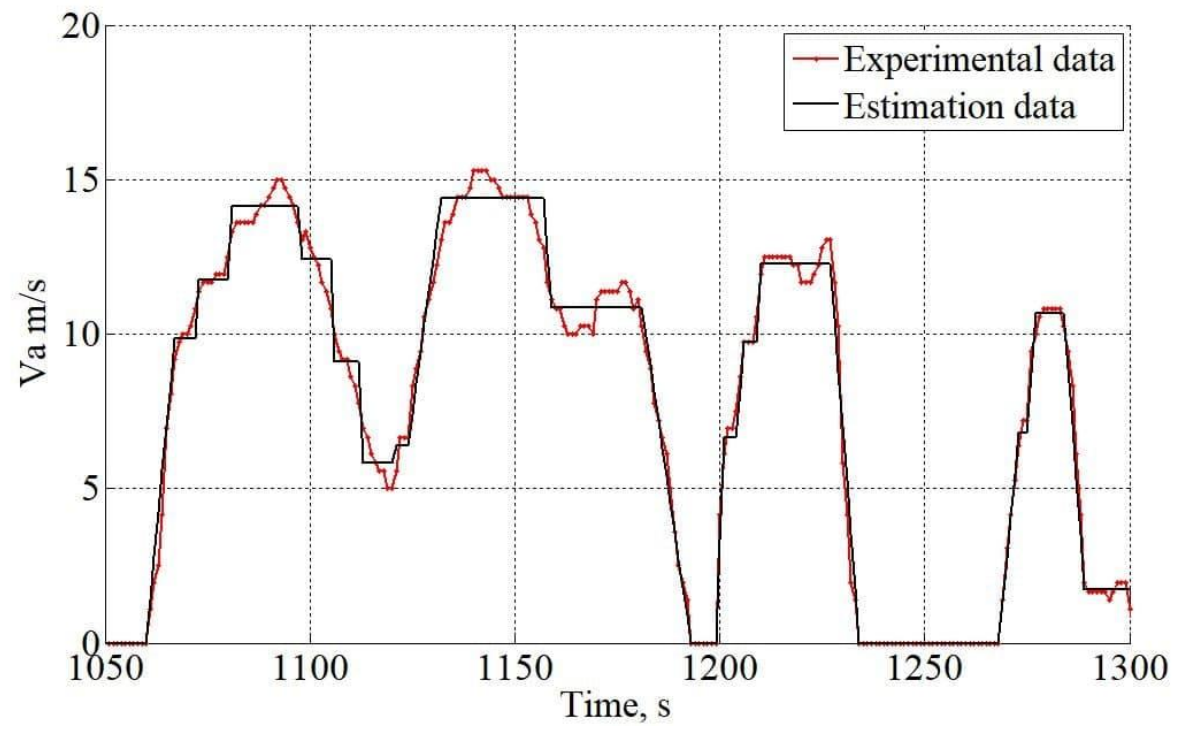

Fig.3. Results of the logical calculation program to determine the values and modes of passenger car traffic

By establishing experimental data, the average values of the traveled path $\mathrm{S}$, velocities $V_{a v}$, acceleration and deceleration $\pm j$, duration of each mode, as well as developed "Computer program for determining the modes and indicators of movement of passenger cars." 


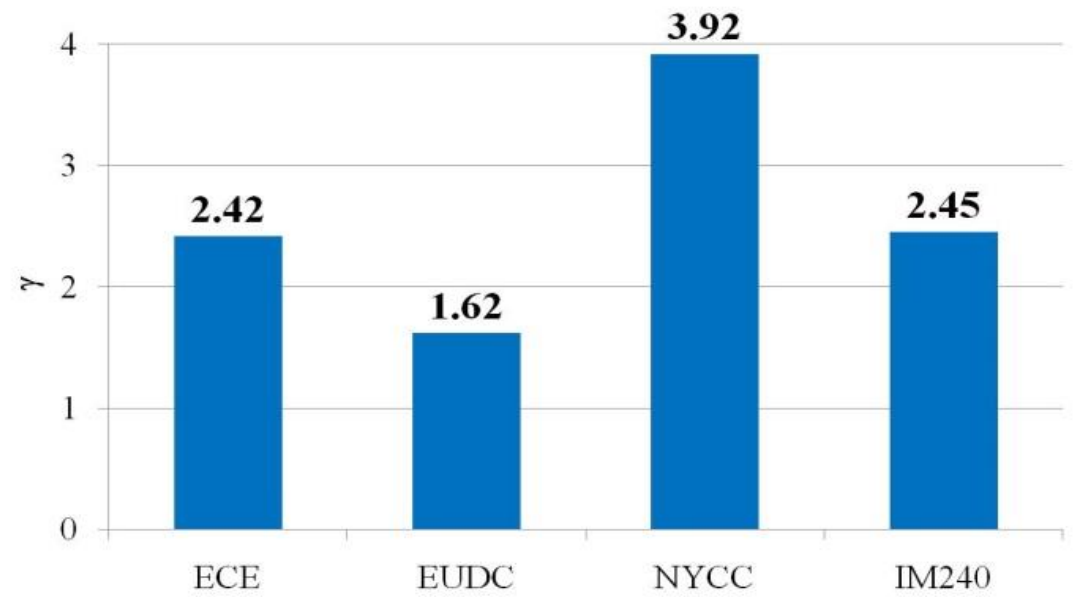

Fig.4. Degree of complexity of the normative driving cycles

The degree of complexity of the driving cycles is evaluated according to the proposed criterion (Fig. 4), which showed the different adaptability of vehicles in terms of fuel consumption to the operating conditions. According to the proposed criterion, "Computer calculation program for evaluating the vehicle and driving conditions by fuel efficiency" was developed for a comparative evaluation of driving cycles.

\section{Conclusion}

As a result of the research on the development of the driving cycle by synthesizing the modes of the car, the following conclusions were formulated:

1. It is established that the existing differences in the driving cycles are due to the ambiguity of the car manufacturer's requirements. These cycles aim to improve the design to improve the properties of the car and do not characterize the real operating conditions. The adaptability of the car to a specific operating condition, determination of fuel economy, environmental friendliness, energy efficiency, and many other qualities predetermine the need to develop an appropriate driving cycle.

2. It was revealed that the existing regulatory driving cycles ECE, EUDC, NYCC, IM240, used in determining the fuel economy and environmental performance of cars in urban conditions, differ in degree of complexity. Against the background of the developed methodology, the degree of complexity of the existing cycles ranges from 1.62 to 3.92.

3. The range of changes in the average technical speed of passenger cars was determined by the method of analysis developed based on statistical data of traffic modes of cars in urban conditions. From July 2018 to July 2019, the average technical speeds of passenger cars in the number of more than 50 units were determined. As a result, the average speed for Tashkent city is $25.9 \mathrm{~km} / \mathrm{h}$, with ranges of changes by hours of the day $11.2 \%$, by days of the week $-6.2 \%$, by seasons $-3.1 \%$.

4. The proposed method of synthesizing vehicle driving modes allows differentiated determination of vehicle driving cycles, taking into account the specific conditions of their operation. 


\section{References}

1. Kropiwnicki, J., Kneba, Z. \& Ziółkowski, M. Test for assessing the energy efficiency of vehicles with internal combustion engines. Int.J Automot. Technol. 14, pp 479-487 https://doi.org/10.1007/s12239-013-0052-9.(2013).

2. Kutani Ichiro. Addressing Energy Efficiency in the Transport Sector Through Traffic Improvement. ERIA Research Project Report 2016, 04. https://thinkasia.org/bitstream/handle/11540/7439/RPR_FY2016_04.pdf?sequence=1. (2016).

3. Козлов, А.В. Современные требования $\kappa$ уровню энергетической эффективности транспортных средств, А.В. Козлов, А.С. Теренченко // $\begin{array}{lllll}\text { Журнал автомобильных } & \text { инженеров. } & 2014 . & 1 & \text { (84). }\end{array}$ https://elibrary.ru/item.asp?id=21992560. (2014).

4. Regulation (EC) № 443/2009 of the European Parliament and of the Council Setting Emission Performance Standards for New Passenger Cars as Part of the Community's Integrated Approach to Reduce CO2 Emissions from Light-Duty Vehicles. - 23 April 2009. p 15.

5. An, F., Gordon, D., He, H., Kodjak, D. and Rutherford, D. (July 2007). Passenger vehicle greenhouse gas and fuel economy standards: A global update. Washington DC: The International Council on Clean Transportation. (2007).

6. MSC 2012 MSC.EASY5. Ricardo Powertrain Library. Simulation tools to analyze powertrain system performance. MSC.Software Corporation. http://www.mscsoftware.com/assets/2012_e5303zpwrlzltdat.pdf. (2012).

7. Kasab, J. and Velliyiur, S. (13 April 2012. Addendum: 17 May 2012). Analysis of greenhouse gas emission reduction potential of light duty vehicle technologies in the European Union for 2020-2025. Washington DC: Project report of Ricardo Inc. on behalf of the International Council on Clean Transportation. (2012).

8. Kasab, J., Shepard, D. and Velliyiur, S. (25 January 2013). User guide for Data Visualization Tool. Washington DC: Report of Ricardo Inc. on behalf of the International Council on Clean Transportation. (2013).

9. G. Souffran, L. Miegeville, and P. Guerin, "Simulation of real-world vehicle missions using a stochastic markov model for optimal powertrain sizing," IEEE Transactions on Vehicular Technology, 61, (8), pp. 3454-3465, (2012).

10. J.-M. Zaccardi and F. Le Berr, "Analysis and choice of representative drive cycles for light duty vehicles - Case study for electric vehicles, " Proceedings of the Institution of Mechanical Engineers, Part D: Journal of Automobile Engineering, 227, (4), pp. 605616, (2013).

11. Guzzella, L.; Sciarretta, A. Vehicle Propulsion Systems. Introduction to Modeling and Optimization. SpringerVerlag: Berlin, Germany, p 418. (2013).

12. M. Andre, R. Joumard, R. Vidon, P. Tassel, and P. Perret, "Real-world European driving cycles, for measuring pollutant emissions from highand low-powered cars," Atmos. Environ., 40, (31), pp. 5944-5953, (2006).

13. T. Nutramon and C. Supachart, "Influence of driving cycles on exhaust emissions and fuel consumption of gasoline passenger car in Bangkok," J. Environ. Sci., 21, (5), pp. 604-611, (2009).

14. G. Amirjamshidi and M. Roorda, "Development of Simulated Driving Cycles: Case study of the Toronto Waterfront Area," Transp. Res. Board Annu. Meet., 34, (227), pp. 255-266, (2013).

15. R. Mahayadin et al., "Efficient methodology of route selection for driving cycle development, " in Journal of Physics: Conference Series, (2017). 
16. U. Galgamuwa, L. Perera, and S. Bandara, "Developing a General Methodology for Driving Cycle Construction, Comparison of $\mathrm{Va}$ "Using large driving record samples and a stochastic approach for real-world driving cycle construction, rious Established Driving Cycles in the World to Propose a General Approach," J. Transp. Technol., 5, (5), pp. 191-203, (2015).

17. R. Mahayadin, I. Ibrahim, I. Zunaid, «Development of Driving Cycle Construction Methodology in Malaysia's Urban Road System», International Conference on Computational Approach in Smart Systems Design and Applications (ICASSDA) DOI: 10.1109/ICASSDA.2018.8477619, (2018).

18. Ashtari, E. Bibeau, and S. Shahidinejad, Winnipeg driving cycle, Transportation Science, 48, (2), pp. 170-183, (2014).

19. Berzi, L.; Delogu, M.; Pierini, M. Development of driving cycles for electric vehicles in the context of the cityof Florence. Transp. Res. Part. D Transp. Environ., 47, pp 299-322. (2016).

20. Li, Y.; He, H.; Peng, J. An adaptive online prediction method with variable prediction horizon for futuredriving cycle of the vehicle. IEEE Access 2018, (6), pp 3306233075. (2018)

21. Lin, J. A Markov Process Approach to Driving Cycle Development; University of California, Davis: Davis, CA,USA, (2020). 